\title{
Anatomical, Histological and Histochemical Features of the Guinea Pig (Cavia porcellus) Caecum
}

\author{
Adriana CHENDE ${ }^{1}$, Cristian MARTONOS ${ }^{1 *}$, Adrian-Florin GAL ${ }^{2}$, Vasile RUS ${ }^{2}$, Viorel \\ MICLĂUȘ ${ }^{2}$, Dalma PIVARIU ${ }^{3}$, Ion VLASIUC ${ }^{1}$, Sanda ANDREI ${ }^{4}$, Aurel DAMIAN ${ }^{1}$
}

\author{
${ }^{1}$ Department of Anatomy, Faculty of Veterinary Medicine, University of Agricultural Sciences and Veterinary Medicine \\ Cluj-Napoca, Calea Mănăştur 3-5, Cluj-Napoca, 400372, Romania \\ ${ }^{2}$ Department of Cell Biology, Histology and Embryology, Faculty of Veterinary Medicine, University of Agricultural \\ Sciences and Veterinary Medicine Cluj-Napoca, Calea Mănăştur 3-5, Cluj-Napoca, 400372, Romania \\ ${ }^{3}$ Department of Veterinary Toxicology, University of Agricultural Sciences and Veterinary Medicine, 3-5 Mănăştur \\ Street, 400372 Cluj-Napoca, Romania \\ ${ }^{4}$ Department of Veterinary Chemistry, University of Agricultural Sciences and Veterinary Medicine, 3-5 Mănăştur \\ Street, 400372 Cluj-Napoca, Romania \\ *Corresponding author: Cristian MARTONOS e-mail: cristian.martonos@usamvcluj.ro
}

\section{RESEARCH ARTICLE}

\begin{abstract}
In this study, the caecum of five guinea pigs was anatomically, histologically, and histochemically analyzed. From an anatomical point of view, it has been proved that the caecum in guinea pigs occupies the caudal segment of the abdominal cavity and consists of three parts: the ampullary portion, the body of the caecum, and the apex of the caecum, without a caecal appendix. In our histological analysis, we observed that the caecum has a simple structure, and the cecal mucosal glands are rare and contain, in addition to enterocytes, a small number of goblet cells, which are better represented in the deep part of the glands. Histochemically it has been observed that goblet cells are PAS and Alcian blue positive, which shows that they secrete both neutral and acidic mucins. The intensity of these two histochemical reactions is similar to that of goblet cells from other intestinal segments, proving that they are typical goblet cells. The large volume of the caecum suggests that this is an important section for the digestion process, although the relatively simple structure of the caecal mucosa suggests that the digestion here is not preponderant, but only complements the intestinal one.
\end{abstract}

Keywords: guinea pig; Cavia porcellus; caecum.

Received: 28 August 2020 Accepted: 09 March 2021

Published: 14 May 2021

DOI:

10.15835/buasvmcn-vm:2020.0015

(c) 1 (3) (9) 2021 Authors. The papers published in this journal are licensed under the Creative Commons Attribution-NonCommercialNoDerivatives 4.0 International License

\section{INTRODUCTION}

In the literature, we can find a description of some anatomical structural aspects of the digestive tract in the species Cavia porcellus, about the structure of prediaphragmatic digestive segments (Rus et al. 2019; Ciena et al. 2017) and the structure of the small intestine (Al-Saffar and Nasif, 2019). Another topic quite often addressed in the case of guinea pigs is represented by the adnexal glands of the digestive tract (Matosz et al. 2016).

As for the caecum, it is described in the literature as the first segment of the large intestine, which makes the connection between the ileum and the ascending colon (Stan, 2018; Stan, 2014; Stan et al., 2014; Barone, 1997; Snipes, 1982).

Taxonomically, the guinea pig was classified as a species at the end of the 17th century and is due to a naturalist named Johann Polycarp Erxleben. The guinea pig is part of the Animalia Kingdom, Cordata, Mammalia Class, Rodentia Order, Hystricomorpha Suborder, Caviidae Family, Caviinae Subfamily, Cavia Genus (Marcus și col., 2018). The Suborder Hystricomorpha also includes animals such as chinchillas, hedgehogs, capybara, and even some porcupines-like small rodents. The morphological peculiarities of the animals included in this subordination are the presence of a zygomatic arcade and a wide infraorbital canal. Animals belonging to 
the Caviidae family are characterized by the presence of 4 fingers on the forelimbs and 3 toes on the hindlimbs.

The initial reason, the guinea pig was placed in the Rodentia order was that this animal tends to gnaw on something all the time. In recent years, other opinions have emerged regarding the guinea pig's membership in rodents. Following molecular biology research, some researchers have concluded that the chemical structure of insulin in guinea pigs differs from the chemical structure of insulin, in other mammalian species (Harkness et al., 2002; Carleton et al., 2005). Following these findings, some researchers have proposed moving the guinea pig to a separate mammalian order called polyphilic rodents (Graur and Li, 1991). These discoveries and proposals have managed to trigger many controversies, but the vast majority of researchers claim that this animal is correctly classified as a rodent. To argue that the taxonomic classification of guinea pigs is correct, they rely on the fact that rodent-specific nucleotide sequences have been identified in Cavia porcellus (Konno et al., 1999).

This study aims to expose as early as possible the macroscopic, histological, and histochemical aspects of caecum to the species Cavia porcellus.

\section{MATERIALS AND METHODS}

The biological material used in this study was represented by 5 adult guinea pigs, of which 3 females and 2 males. The animals used in this investigation were presented at the Histopathology Laboratory of the National Sanitary Veterinary and Food Safety Agency of Romania in Salaj, Zalau for diagnosis. We mention that these animals were dead prior to our study, so we did not use live animals. In this situation we can say that through the working protocol approached, we complied with Law no. 43/2014 on the protection of animals used for scientific purposes.

For the anatomical investigations, the classic dissection method was used, in such a way as to allow the highlighting in the best conditions of the organs, that make up the digestive system in guinea pigs. We made a detailed study about the caecum, we isolated the anatomical segment, and photographed with a digital camera, Nikon D 3400 for obtaining the macroscopic images, and a detailed anatomical description was made. For histological and histochemical investigations fragments from the caecum were collected and fixed with $10 \%$ formalin for three days, with daily change of the fixative solution. Subsequently, the parts were dehydrated with ethyl alcohol of increasing concentration. The sample clarification was done with butyl alcohol (1-Butanol), by passing the samples through three baths of 24 hours each (Mureșan și col., 1974), followed by inclusion, by passing successively through three baths of paraffin at $56^{\circ} \mathrm{C}$, with time parking 1 hour in each bathroom.

After pouring into paraffin blocks, histological sections with a thickness of 5 micrometers were practiced, on which histological and histochemical staining was performed. For histological investigations, the Goldner trichrome staining was performed (Gabe, 1968), and for the histochemical investigations, the PAS reaction and the staining with Alcian blue at $2,5 \mathrm{pH}$ were used (Kienan, 1990). The examination of histological and histochemical preparations was done with an Olympus BX41 microscope, and the capture of microscopic images was done with aid of an Olympus E330 digital camera. The final processing of the histological images was done with the Adobe Photoshop 2020 program.

\section{RESULTS AND DISCUSSIONS}

From an anatomo-topographic point of view (Figure 1), in the case Cavia porcellus, the caecum occupies the caudal segment of the abdominal cavity, having a transverse arrangement.

Considering the macroscopic aspects, we can say that the caecum consists of three parts: the ampullary portion (Basis ceci), oriented to the left, the body (Corpus ceci), obliquely arranged, and the apex of the caecum (Apex ceci), slightly oriented ventro-cranio-medial on the right side. In none of the subjects, the caecum didn't present a cecal appendix.

The largest caliber of the caecum is the ampullary portion, and then gradually decreases to the apex of the organ. It has on the surface three longitudinal muscle bands (Teniae ceci) that cross the medial face, the lateral face and the ventral face of the caecum. Since the length of the cecum is greater than the length of the three muscle bands, a series of bumps appear on its surface. As a shape, the guinea pig cecum has the appearance of an elongated dilation that ends like a blind sac. It communicates with the ileum (Ileum) through the ileocecal orifice (Ostium ileale), and with the ascending colon (Colon ascendens) through the ceco-colic orifice (Ostium cecocolicum). The two openings are very close in the case of the guinea pig and appear arranged on the small curvature (Curvatura ceci minor), between the ampullary portion and the body of the caecum.

The body of the caecum is fixed to the ileum through the ileocecal ligament, and the middle portion of the caecum is connected to the ascending colon through the ceco-colic ligament. 


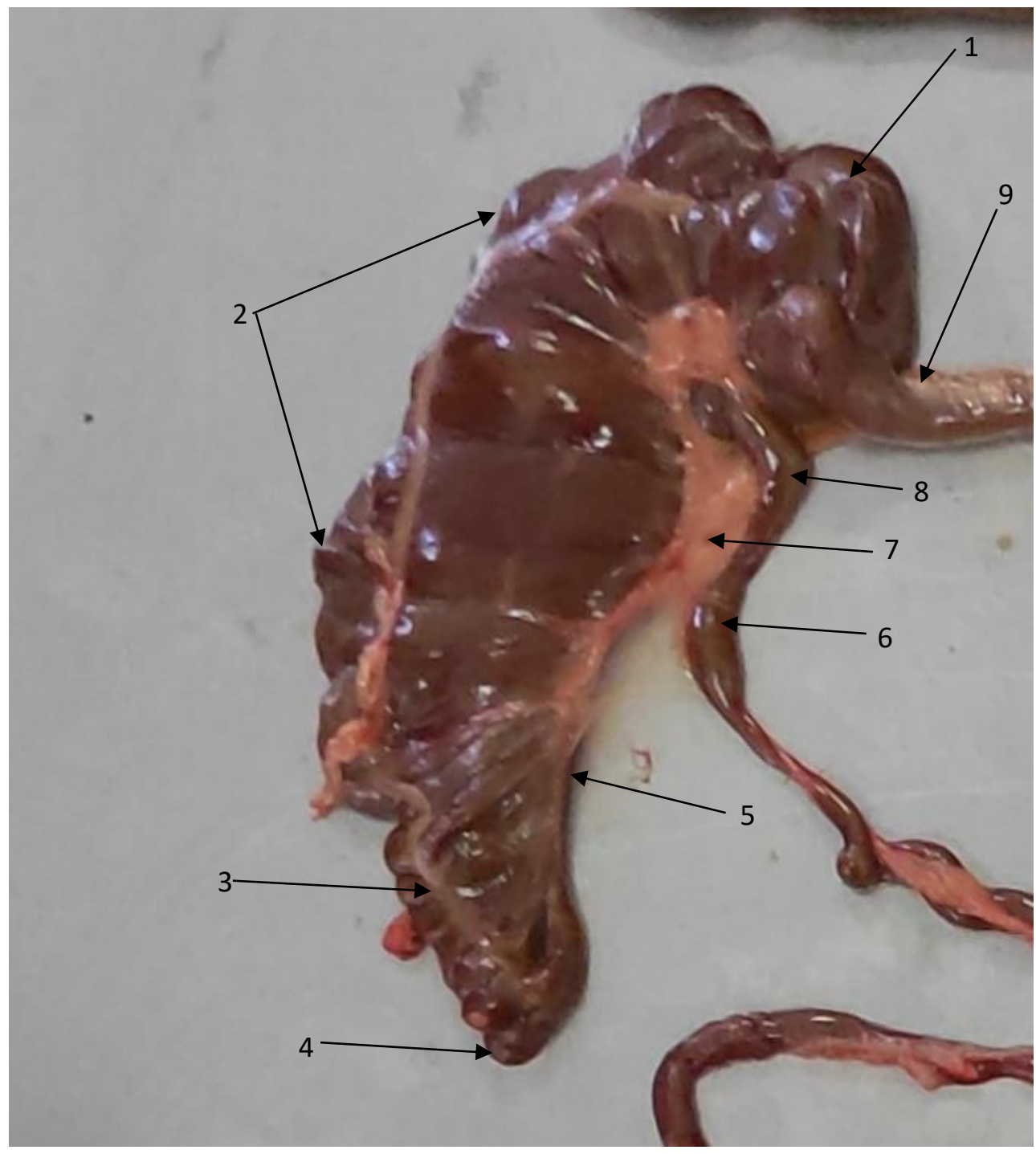

Figure 1. The caecum in guinea pigs, macroscopic aspects. 1. The ampullary portion of the caecum; 2. The body of the caecum; 3. Lateral caecal taenia; 4. The apex of the caecum; 5. Medial caecal taenia; 6. The ileon; 7. Ileo-cecal ligament; 8. The ileon; 9. The ascending colon.

Histologically (Figure 2), in the guinea pig, the caecum has a thin wall. The mucosa is the most developed component of the cecal wall and contains the surface epithelium, glands, lamina propria, and muscularis mucosae. The mucosa is the most developed component of the cecal wall and contains the surface epithelium, mucosal glands, lamina propria, and muscularis mucosae. At this level, there are crypts similar to the ones of the stomach. In the thickness of the mucosa exists typical intestinal glands, arranged from the bottom of the crypts to the muscular mucosae. However, their number is significantly lower than in the small intestine. The surface epithelium consists of enterocytes with microvilli arranged in a single row on the basement membrane. Glandular epithelium forms glove finger-like structures that generate mucosal glands, that are arranged from the surface epithelium to the muscularis mucosae, on which they are aligned with the fundic portion. The first part of the glands appears with a wide lumen, that narrows visibly so that the opening of the glands is somehow similar to the appearance of the crypts in the stomach. We noticed that the cells that line these small crypts seem identical to those on the surface of the mucosa. The wall of the glands is made up of morphologically similar cells that make a simple columnar epithelium. These glands are of medium length and appear arranged at a certain distance from each other so that the lamina propria between them is well represented and has a prominent cellular infiltrate. In the studied individuals, the walls of intestinal glands presented isolated goblet cells along with enterocytes.

The muscularis mucosae is thin but continuous, the submucosa contains a loose connective tissue, and muscularis externa appears arranged in two layers, circular internally and longitudinal externally. 


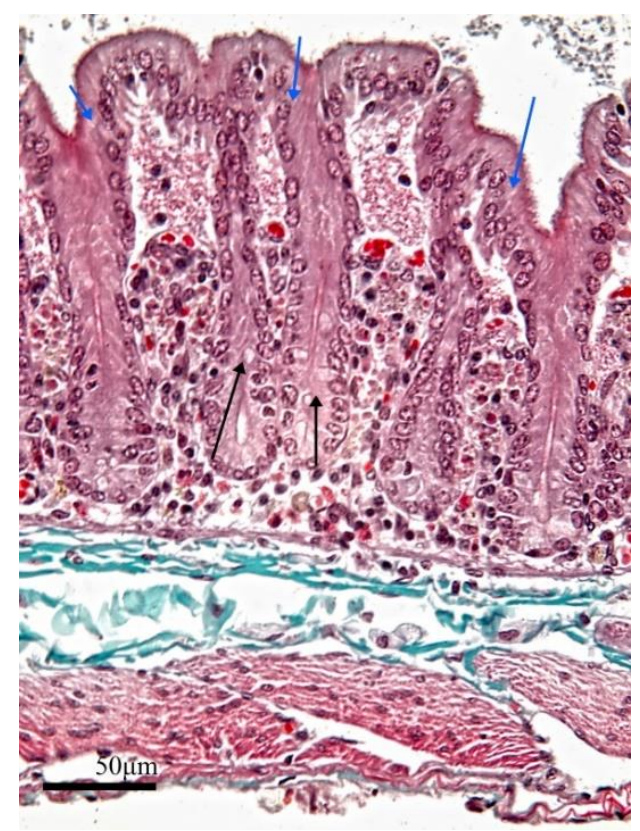

Figure 2. The caecum in guinea pigs, histological features (Goldner's trichrome stain): enterocytes (blue arrows), and intestinal glands (black arrows).

From a histochemical point of view, on the PAS reaction (Figure 3), we observed that only the goblet cells were PASpositive, which appear in very small numbers in the surface epithelium and are somewhat better represented in the glandular one, especially in the deeper third of the glands. Regarding the acidic mucins, they were identified only in the goblet cells of the intestinal glands that were Alcian-blue positive (Figure 4).

The caecum is located on the left side of the abdomen, is $15-20 \mathrm{~cm}$ long in the guinea pigs, and has three muscular bands.

The anatomical and topographical aspects reported by us are similar to those reported in guinea pigs by Stan, 2018 and Snipes's,1982. Another species with a relatively similar arrangement of the caecum is the pig (Mireșan, 2009; Barone, 1997).

Unlike guinea pigs, in rats (Stan, 2018) the caecum is arranged on the right side, but more cranial. In the species Cavia porcellus, the caecum is a pouch-like organ, with thin walls and can store more than $65 \%$ of the contents of the digestive tract (Kohles, 2014).

Some authors claim that in guinea pigs, most of the digestion takes place in the caecum, and the gastrointestinal transit time in guinea pigs occurs in about 13 to 30 hours (Marcus et al., 2018).

The caecum in the guinea pigs has a thin wall, with a very simple structure and no villi. In addition to enterocytes, the walls of the cecal mucosal glands present a smaller number of goblet cells than in the other intestinal segments, but from a histochemical point of view, they behave similarly concerning the PAS and Alcian blue reactions. This proves that the goblet cells in the caecum of guinea pigs are identical to the ones from the other intestinal segments.

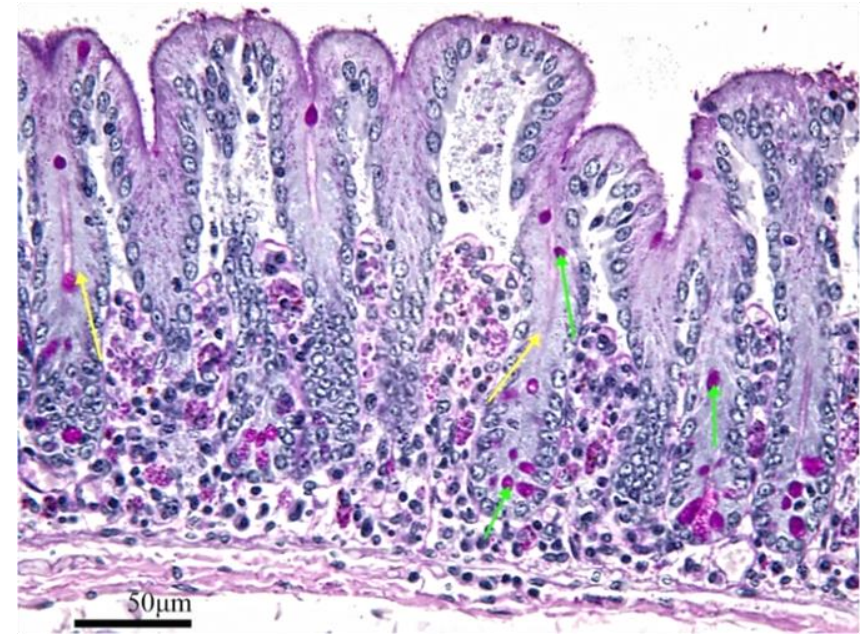

Figure 3. The caecum in guinea pigs, PAS reaction: PAS-positive goblet cells (green arrows), and intestinal glands (yellow arrows). 


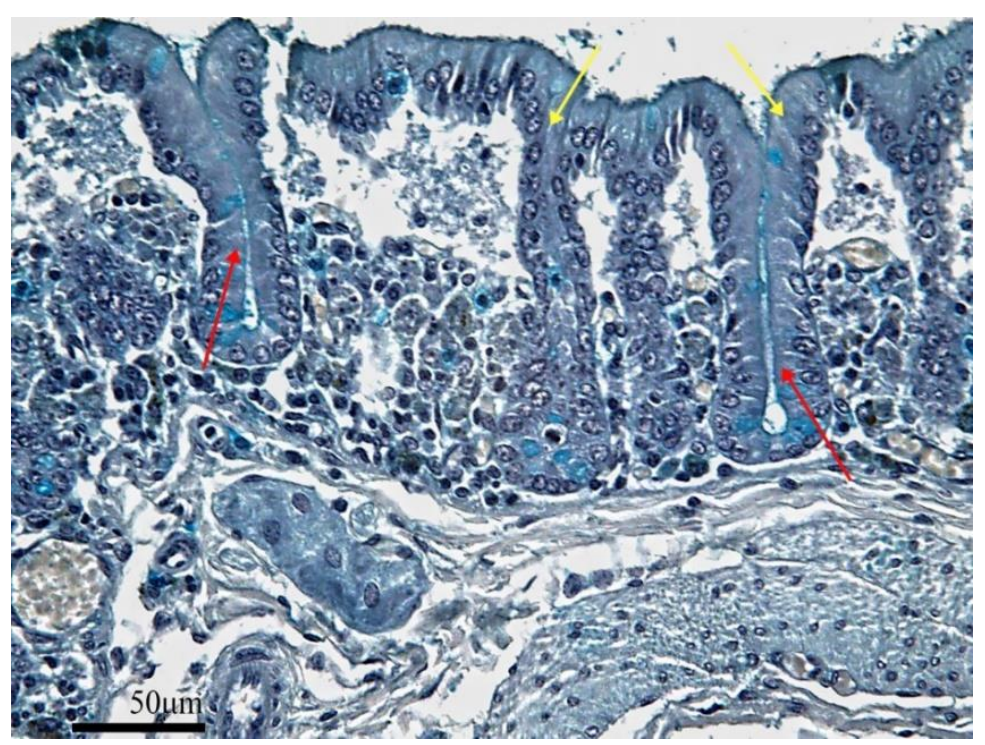

Figure 4. The caecum in guinea pigs, Alcian-blue staining: enterocytes (yellow arrows), intestinal glands (red arrows) that includes Alcian-blue positive goblet cells.

Overall, the cecal mucosa in guinea pigs has a relatively simple structure, which cannot fully support the statement of some researchers, namely that in rodents, the digestion takes place mostly at the level of the caecum (Snipes, 1982). It is known that certain components of feed cannot be digested in the small intestine due to their more particular structure. We refer here to lignin, cellulose, etc., which can be disintegrated only at the level of the caecum mostly by fermentative rather than by enzymatic processes. Accordingly, such food components are decomposed in the caecum, and the resulting principles are absorbed here. The simple structure of the caecum in guinea pig may suggest that local digestion can't decompose the vast majority of the food (Kohles, 2014). Following these aspects, we can say that cecal digestion in guinea pigs only completes the intestinal digestion, which is predominant.

\section{CONCLUSIONS}

The caecal wall in guinea pigs has a simple structure that includes mucosa, submucosa, muscularis externa, and serosa. The mucosa consists of surface epithelium mainly made of enterocytes with microvilli, and relatively rare glands in the depth of the mucosa, glands lined by enterocytes, and few goblet cells. The goblet cells in the caecum of the guinea pig are positive for both the PAS and Alcian blue reactions, which suggests they synthesize both neutral and acidic mucins.

Author Contributions: A.C. Collected the data; C.M. Conceived and designed the analysis; A.-F. G. was involved in the histopathological data analysis; V.R. drafted the manuscript and coordinated the interpretations; V.M. Completed the manuscript and revised the article; D.P. helped to write the manuscript and completed the data analysis; I.V. Performed the analysis; S.A. helped to complete the revised article; A.D. Contributed data and analysis tools.

\section{Acknowledgments}

This paper was realized with the help of the University of Agricultural Sciences and Veterinary Medicine.

This research did not receive any specific grant from funding agencies in the public, commercial, or not-for-profit sectors.

\section{Conflicts of Interest}

The authors declare that they do not have any conflict of interest.

\section{REFERENCES}

1. Al-Saffar FJ and Riyadh Hameed Nasif. Histoarchitecture and Histochemical Study of the Duodenum in Adult Guinea Pigs (Cavia porcellus). Indian Journal of Natural Sciences. 2019; 10(57): 17815- 17824.

2. Barone R. Anatomie comparée des mammifères domestiques. Splanchnologie I. Appareil digestif, appareil respiratoire. 3th ed. Paris: Vigot Fréres, vol. 3; 1997

3. Carleton MD, Musser GG. Order Rodentia, In Mammal Species of the World, 3rd edition, Volume 3, p. 745; 2005

4. Ciena AP, Santos ACD. Vasconcelos BG, et al. Morphological characteristics of the papillae and lingual epithelium of guinea pig (Cavia porcellus). Acta Zool. 2017; 1-8. Available from: https://doi.org/10.1111/azo.12230. 
5. Gabe M. Techniques histologiques, editurs Masson et $\mathrm{C}^{\mathrm{ie}}$, Paris; 1968.

6. Graur C, Li W. Is the guinea pig a rodent?. Nature 1991; 351:649-652.

7. Harkness JE, Murray K., Wagner JE. Biology and diseases of guinea pigs, In: Fox J.G., Anderson L.C. Lowe F.M., Quimby F.W., (Eds), Laboratory Animal Medicine, second ed. Academic Pres, San Diego, p. 203-246; 2002.

8. Kiernan JA. Histological and histochemical methods: Theory and practice, Ed. 3, Butterworth Heinemann, Oxford, UK, pp. 170-196; 1999

9. Kohles M. Gastrointestinal Anatomy and Physiology of Select Exotic Companion Mammals, Vet Clin Exot Anim. 2014; 17:165-178.

10. Konno Ryuichi, Atsushi Kurabayashi, Masaru Tsuchiya, Akira Niwa. Guinea Pig D-Amino-Acid Oxidase cDNA and Phylogenetic Position, DNA Sequence. 1999; 10(2):85-91. Available from: DOI:10.3109/10425179909008422.

11. Marcus I, Sevastre B, Sarpataki O. Biology and pathology of laboratory animals, Ed. Risoprint, Cluj-Napoca, 2018.

12. Matosz B, Luca V, Dezdrobitu CC, Martonos C, Damian A. Major salivary glands topography in Guinea Pigs (Cavia porcellus), Agriculture, Science and Practice. 2016; 1-2:97-98.

13. Mireșan V. Comparative Anatomy, Histology and Embryology, Ed. AcademicPres, Cluj-Napoca, România; 2009

14. Mureșan E, Bogdan AT, Gaboreanu M, Baba AI, Normal and pathological histochemistry techniques, Ed. Ceres, București, pp. 271; 1976

15. Nomina Anatomica Veterinaria. 6th Edition- Revised; 2017.

16. Snipes RL. Anatomy of the guinea-pig cecum. Anatomy and Embryology. 1982; 165: 97-111. Available from: http://dx.doi. org/10.1007/BF00304586.

17. Stan FG (2014). Anatomical particularities of the cecum in rabbits and chinchillas, Bulletin UASVM Veterinary Medicine. 2014; 71(2):406-412.

18. Stan FG. A Comparison Between the Macroscopic Anatomy of the Cecum in Laboratory Rat and Guinea Pig, Bulletin UASVM Veterinary Medicine. 2018; 75(1):131-132.

19. Stan FG, Damian A, Gudea A, Dezdrobitu C, Bob D, Martonoş C, Bochis I, Pogana B. Comparative Anatomical Study of the Large Intestine in Rabbit and Chinchilla, Bulletin UASVM Veterinary Medicine. 2014; 71(1):208-212.

20. Rus V, Ruxanda F, Damian A, Nut C, Martonoş C, Dogaru G, Miclaus V, Gal AF. Histological aspects of the esophagus in guinea pigs (Cavia porcellus), Bulletin UASVM Veterinary Medicine. 2019; 76(2):226- 231. 